\title{
Hemşirelerin Koronavirüs İkilemi: Sağıı Mı? Hizmet Mi?
}

Nurses' Coronavirus Dilemma: Health? or Service?

\author{
Çiğdem AKSU1 (D), Ejdane COŞKUN² (D), Burcu ÇAKI ${ }^{3}$ (D), Zeynep GÜNGÖRMÜŞ4 (iD \\ 1 Dr. Öğr.Üyesi, Gaziantep İslam Bilim ve Teknoloji Üniversitesi, Gaziantep, Türkiye \\ ${ }^{2}$ Öğr .Gör., Osmaniye Korkut Ata Üniversitesi, Osmaniye, Türkiye \\ ${ }^{3}$ Arş. Gör., Gaziantep İslam Bilim ve Teknoloji Üniversitesi, Gaziantep, Türkiye \\ ${ }^{4}$ Prof.Dr., Gaziantep İslam Bilim ve Teknoloji Üniversitesi, Gaziantep, Türkiye
}

\section{ÖZ}

\begin{abstract}
Amaç: Bu çalışma Türkiye'deki hemşirelerin pandemi sürecindeki yetkinliklerini, tutumlarını ve psikososyal etkilenme düzeyini belirlemek amacıyla yapılmıştır. Gereç ve Yöntem: Bu kesitsel araştırmanın verileri araştırmacılar tarafından oluşturulan tanıtıcı bilgi formu, hemşirelerin tutumlarını belirlemek amacıyla hazırlanan soru formu ve Acil Durumda Çalışanların Öz Yeterlilik Ölçeği kullanılarak toplandı. Anketler Google forms aracılığı ile dijital ortamda Türkiye'de aktif olarak çalışan hemşirelere 20.04.2020-20.05.2020 tarihleri arasında gönderilerek, araştırma 390 katılımcı ile tamamlandı. Sonuçlar: Hemşirelerin \%95,6'sının işe gitmek dışında gerekmedikçe evden dışarı çıkmadığı, \%86,9'unun evine misafir kabul etmediği, \%80,5'inin ailesi ve 65 yaş üstü yakınları ile görüşmediği belirlenmiştir. Katılımcıların \%23,3'ü çocuğu ile iletişimi konusunda olumsuz duygulara sahip iken; çoğunluğunun çocuğu bulunmamaktadır. Çalışmaya katılan hemşirelerin $\% 36,1$ 'inin bu süreçte eşleri ile ilişkisinde olumsuzluklar yaşadıkları; \%26,7'sinin bu süreçte eşi tarafından desteklendiği belirlenmiştir. Tartışma: Hemşirelerin Koronavirüs-19'a karşı alınan koruma önlemleri ile ilgili tutumlarının olumlu olduğu, büyük çoğunluğunun yetkin, istekli, ilgili aynı zamanda kaygılı oldukları belirlendi. Ailesiyle birlikte yaşayanların hastalığı aile bireylerine bulaştırma korkusu nedeniyle bireysel önlemler aldığı, salgın sürecinde çocukları ve eşi ile olan ilişkilerinde değişiklik yaşadıkları saptandı.
\end{abstract}

Anahtar Kelimeler: Koronavirüs; Bilgi; Hastalık salgınları; Psikoloji; Hemşirelik.

\section{ABSTRACT}

Purpose: This study aimed to determine competence, attitudes, and levels of psychosocial exposure level of nurses duringthe Coronavirus-19 pandemic in Turkey. Material and Methods: Data were collected using an introductory information form created by the researchers, a questionnaire prepared to determine the nurses' attitudes, and Self- Efficacy Scale of Emergency Workers in this cross-sectional study. Surveys were sent digitally via Google forms between April 20th and May 20th 2020 to nurses actively working in Turkey, and the study was completed with the participance of 390 participants. Results: It was determined that $95.6 \%$ of the nurses did not go out of the house unless necessary except to go to work, $86.9 \%$ did not accept guests to their home, and $80.5 \%$ did not meet their families and relatives over 65 years of age. While $23.3 \%$ of the participants had negative feelings about communication with their children, the majority of them did not have children. It was determined that $36.1 \%$ of the nurses participating in the study experienced negativity in their relationship with their spouses, and $26.7 \%$ of them were supported by their spouses during this period. Discussion: It was determined that nurses' attitudes towards the protection measures that need to be taken against the Coronavirus-19 were positive, and most of them were competent, willing, interested and anxious. It was found that those living with their families took individual precautions due to the fear of infecting their family members and experienced changes in their relationships with their children and spouse during the epidemic.

Keywords: Coronavirus; Knowledge; Disease outbreaks; Psychology; Nursing.

Sorumlu Yazar (Corresponding Author): Burcu ÇAKI E-mail: b.caki@hotmail.com ORCID ID: 0000-0002-3592-5121

Geliş Tarihi (Received): 23.11.2020; Kabul Tarihi (Accepted): 26.01.2022

Bu çalışma Uluslararası Avrasya Sağlık Bilimleri Kongresi'nde sözel bildiri olarak sunulmuştur. 
Şu anda bütün dünyayı etkisi altına alan ve büyük bir endişe yaratan Koronavirüs-19 (COVID-19) DSÖ tarafından "Uluslararası Halk Sağlığı Acil Durumu" olarak ilan edilmiştir (Ludwig ve Zarbock,2020; Sağlık Bakanlığı Halk Sağlığı Genel Müdürlüğü, 2020). Bu nedenle birçok toplumda hastalığın hızlı bir şekilde yayılmasını önlemeye yönelik tedbirler alınmıştır (ThinkTech, 2020). Özellikle tedavi ve bakım yükümlülüğü olan sağlık çalışanları için Sağlık Bakanlığı tarafından rehberler yayınlanmış, bu rehberlerde hastanın bakımından sorumlu olan, enfekte veya bulaş riski taşıyan hastalarla en fazla zaman geçiren hemşirelere koronavirüsten korunma yöntemleri kapsamında el yıkama ve sosyal izolasyon konusunda vurgular yapılmıştır.

Yayınlanan rehberler aracılığıyla konuyla ilgili bilgilerin güncellenmeye çalışılması, salgından etkilenen hastaların bakım sürecinde hemşirelerin birçok ikilem ile karşı karşıya kalmasına engel olamamıştır. Hemşirelerin hastanın birebir bakım ve tedavisinden sorumlu olması hizmet sunumunda büyük önem taşımakta iken, kendilerinin ve sevdiklerinin sağlığının risk altında olması, enfekte olma endişesi ve hastalığı bulaştırma korkusu duygusal olarak etkilenmelerine ve stres düzeylerinin artmasına neden olmaktadır (Ho, Chee ve Ho, 2020).Çin'de sağlık çalışanları ile yapılan çok merkezli bir çalışmada, çalışanların \%50,7'inde depresyon, $\% 44,7$ 'sinde anksiyete ve $\% 73,4$ 'ünde stres belirtilerinin olduğu bulunmuş ve bu çalışma sonucu da sağlık mı yoksa hizmet mi ikilemini ortaya koymuş, uzayan çalışma saatleri, stres, yorgunluk ve tükenme gibi birçok faktörün nitelikli ve kaliteli bakım vermeye engel olduğu belirtilmiştir (Xiang, Yang, Live ark., 2020; WHO, 2020a).

Salgın sonrasında alınan tedbirler iş dışında aile hayatında da rolleri ve sorumlulukları olan hemşireleri de kapsamaktadır. Sağıı çalışanları içerisinde önemli bir yere sahip olan hemşirelerin yaşadığı tek ikilem sağlık mı hizmet mi ikilemi değildir. Çalışma saatlerinin düzensizliği, bulaşma/bulaştırma riski gibi faktörler hemşirelerin aile ve çocuklarıyla iletişimlerini etkilemiş, sosyal destek sistemlerini de bozarak ortaya çıkan kaygı ve korkunun şiddetinin ve etkisinin artmasına neden olmuştur (Güvenç ve Baltacı, 2020).

Bu nedenle hemşirelerin COVID-19 hastalığını acil bir durum olarak algılamaları ve hastane ortamında ve sosyal hayatta hastalıktan korunmaya yönelik alınan önlemler hakkındaki tutumları, bu alandaki yetkinlikleri önem kazanmıştır. Salgın sırasında acil tedavi ve bakıma intiyaç duyan hasta bireye gereken bakımı sağlayan hemşireler, karşılaştıkları bu acil durumla mücadelede sahip oldukları ve rehberlerle güncelledikleri bilgi düzeylerine ve acil durumlarda öz yeterliliklerine güvenmek zorundadırlar. Bu anlamda öncelikle durum saptamak amacıyla hemşirelerin bilgi düzeylerinin ve acil durumlarda öz-yeterlilik düzeylerinin belirlenmesi, bu alanlardaki olası eksikliklerinin giderilmesi anlamında gerekli görülmüştür. $\mathrm{Bu}$ araştırma, hemşirelerin pandemi sürecindeki yetkinliklerini, tutumlarını ve psikososyal etkilenme düzeyini belirlemek amacıyla yapılmıştır.

\section{GEREÇ VE YÖNTEM}

Kesitsel tasarıma sahip bu çalışmada, COVID-19 pandemisi nedeniyle veriler yüz-yüze görüşme yöntemiyle toplanamamıştır. Türkiye'de kamu ve özel sağlık kurumlarında aktif olarak çalışan hemşirelere araştırmacılar tarafından Google forms aracılığıyla hazırlanan anket formu online ağlar üzerinden linklerle iletilmiştir. Türkiye'de TÜIKK 2018 verilerine göre toplam sağlık personeli sayısı 1 milyon 16.401 'dir. Hemşireler,sağlık personelinin \%18'ini oluşturmaktadır (TÜIK, 2019).Sağılı Bakanlığı tarafından açıklanan son resmi rakamlara göre, Türkiye'de görev yapmakta olan toplam hemşire sayısı 198.465 'tir (Sağlık Bakanlığı Sağlık Hizmetleri Genel Müdürlüğü, 2021). Bu bilgiler doğrultusunda, evrenin temsili için \%95 güven aralığı ve \%3 hata payı ile minimum 313 kişinin araştırma örneklemine alınması gerektiği hesaplanmış (Schaeffer ve ark., 1990) ve çalışmada toplam 390 hemşireye ulaşıımıştır.

Veri toplama araçları olarak; 25 Mart 2020'de Sağlık Bakanlığı'nın yayınladığı güncel COVID-19 pandemisinde sağlık çalışanları rehberi göz önüne alınarak araştırmacılar tarafından oluşturulan bireylerin tanıtıcı özelliklerini, tutumlarını ve duygu durumlarını belirlemek için kullanılan veri toplama formu ve Acil Durumlarda Çalışanların Öz Yeterliliği Ölçeği kullanılmıştır. Veriler 20.04.2020-20.05.2020 tarihleri arasında araştırmaya katılmaya gönüllü olan 390 hemşire ile tamamlanmıştır.

Acil Durumlarda Çalışanların Öz Yeterliliği; Yalçın (2018) tarafından acil durum programı uygulayanların öz-yeterliliklerini değerlendirmek için geliştirilmiştir. Yapılan analizler ile güvenilir ve geçerli olduğu saptanan, “yetkinlik","ilgi" ve "istek" olarak üç ayrı faktörden oluşan toplam 19 maddelik ve 5 'li likert tipi olan bir ölçektir. Madde puanlaması "Kesinlikle katılıyorum = 5" ile "Kesinlikle katılmıyorum = 1" arasında değişmektedir. Ölçeğin faktör yapı ve 
geçerlik-güvenirlik çalışması Yalçın (2018) tarafından yapılmıştır.

Yapılan çalışmada 3 faktör bulunmuştur. Bunlar; "Yetkinlik", "İstek" ve "İlgi"dir. Yetkinlik Faktörü: Katılımcı yanıtlarının 18 puan altında kaldığı; İstek Faktörü: katıımcı yanıtlarının 18 ve üstü puan olduğu; İlgi Faktörü: katılımcı yanıtlarının 10 puan altında kaldığı durumlarda, acil durum ekiplerine seçilmeyeceği belirtilmektedir. Birincil faktör olan 'istek' maddeleri değerlendirildikten sonra diğer madde puanları değerlendirilir. Ölçeğin Cronbach Alfa güvenirlik analizi sonuçlarına göre, faktörlere ait Cronbach Alfa katsayıları "Yetkinlik" 0,90 , “İstek" 0,76 ve "ilgi" 0,63 olarak bulunmuştur (Yalçın, 2018).

Çalışmada kullanılan ölçek Acil Durumlarda Çalışanların Öz Yeterliliği temel alınarak COVID19 salgınına uyarlanmıştır. Ölçeğin Cronbach Alfa değeri 0,88 bulunmuştur. Faktörlere ait Cronbach Alfa katsayıları "Yetkinlik" 0,88 , "İstek" 0,66 ve "İlgi" 0,69 bulunmuştur.

Veriler SPSS 21.00 paket programında değerlendirilmiştir. Ölçeğin güvenilirliğinin araştırılmasında Cronbach Alfa katsayısı kullanılmıştır. Çalışmada t testi, sayı ve yüzde, korelasyon testi, üç ve daha fazla grup karşılaştırmalarında One-way ANOVA testi, posthoc analizleri için homojen dağılanlarda LSD, homojen dağılmayanlarda Dunnet T3 kullanılmıştır.

Araştırma kapsamına alınan hemşirelere araştırmanın yapılma sebebi ve araştırmanın önemi hakkında gerekli açıklamalara online ortamda hazırlanan anket formunun giriş kısmında yer verilmiş ve her katılımcıdan onam alınmıştır.
Online anket yolu ile uygulanan araştırma için; Sağlık Bakanlığı'ndan "19.05.2020 tarihli 2020-0515T22_05_19 sayılı" ve ilgili üniversitenin etik kurulundan "30.04.2020 tarihli 2020/142 sayılı" etik kurul kararı ile onay alınmıştır. Araştırma Helsinki Bildirgesi ilkelerine uygun olarak yürütülmüştür.

\section{SONUÇLAR}

Araştırmaya katılan hemşirelerin Acil Durumlarda Çalışanları Öz Yeterliliği Ölçeği yetkinlik alt boyutundan $33,9 \pm 7,3$, istek alt boyutundan $17,2 \pm 4,5$ ve ilgi alt boyutundan $14,2 \pm 3,4$ puan aldıkları saptanmıştır (Tablo 1).

Çalışmaya katılan hemşirelerin; yaş ortalamaları $28,1 \pm 6,7$ yıldır ve $\% 81,3$ 'ü kadındır. Katılımcıların\%61,3'ünün devlet hastanesinde çalıştığı, \%88,2'nin herhangi bir kronik hastalığı olmadığı, \%71,5'inin hiç sigara içmediği ve \%61,3'ünün ailesinde yaşı ya da kronik hastalığı olan birey bulunmadığı tespit edilmiştir (Tablo 2). Hemşirelerin sigara alışkanlığı ile yetkinlik ve ilgi alt boyutları arasında istatistiksel olarak anlamlı bir farklılık saptanmıştır $(p<0,05)$ (Tablo 2). Yapılan post-hoc analiz sonucunda sigara içen ve hiç sigara içmeyen hemşirelerin yetkinlik ve ilgi alt boyutlarında aldıkları puanların ortalamaları bu süreçte sigarayı bırakan hemşirelerin aldıkları puan ortalamalarından anlamlı derece yüksek bulunmuştur $(p<0,05)$. Aynı zamanda hiç sigara içmeyen hemşirelerin yetkinlik alt boyut puan ortalaması bu süreçten önce sigarayı bırakan hemşirelerin puan ortalamasından, bu süreçten önce sigarayı bırakan hemşirelerin ilgi alt boyutu puan ortalaması bu süreçte sigarayı bırakan hemşirelerin puan ortalamasından anlamlı derecede yüksektir $(p<0,05)$.

Tablo 1. Hemşirelerin Acil Durumlarda Çalışanların Öz Yeterliliği Ölçeği alt boyut puanları.

\begin{tabular}{ccc}
\hline Alt Boyutlar & Min-Max & Ort $\pm S S$ \\
\hline Yetkinlik & $9-45$ & $33,9 \pm 7,3$ \\
\hline İstek & $6-30$ & $17,2 \pm 4,5$ \\
\hline İlgi & $4-20$ & $14,2 \pm 3,4$
\end{tabular}


Tablo 2. Hemşirelerin tanımlayıcı özellikleri ile acil durumda çalışanların öz yeterlilikleri arasındaki ilişki $(n=390)$.

\begin{tabular}{|c|c|c|c|c|c|}
\hline & & $n(\%)$ & YETKİNLİK & ISTEK & İLGí \\
\hline Yaş (yıl) & $28,1 \pm 6,7$ & $390(100)$ & $r=-0,35, p=0,48$ & $r=0,61, p=0,23$ & $\begin{array}{l}r=0,02, \\
p=0,62\end{array}$ \\
\hline Cinsiyet & $\begin{array}{l}\text { Kadın } \\
\text { Erkek }\end{array}$ & $\begin{array}{l}317(81,3) \\
73(18,7)\end{array}$ & $\begin{array}{l}34,3 \pm 6,7 \\
32,2 \pm 9,2\end{array}$ & $\begin{array}{l}17,3 \pm 4,3 \\
17,0 \pm 5,5\end{array}$ & $\begin{array}{l}14,4 \pm 3,1 \\
13,4 \pm 4,3\end{array}$ \\
\hline Test ve Anlamlılık & & & $\begin{array}{l}t=1,84 \\
p=0,06\end{array}$ & $\begin{array}{l}t=0,31 \\
p=0,75\end{array}$ & $\begin{array}{l}t=1,87 \\
p=0,06\end{array}$ \\
\hline \multirow[t]{3}{*}{$\begin{array}{l}\text { Görevli Olduğu } \\
\text { Sağlık Kuruluşu }\end{array}$} & $\begin{array}{l}\text { Devlet hastanesi } \\
\text { Aile sağlığı } \\
\text { merkezi }\end{array}$ & $\begin{array}{l}239(61,3) \\
25(6,4)\end{array}$ & $\begin{array}{l}33,7 \pm 1,2 \\
31,7 \pm 9,1\end{array}$ & $\begin{array}{l}16,9 \pm 4,2 \\
16,7 \pm 5,7\end{array}$ & $\begin{array}{l}14,1 \pm 3.4 \\
13,4 \pm 4,1\end{array}$ \\
\hline & $\begin{array}{l}\text { Üniversite } \\
\text { hastanesi }\end{array}$ & $72(18,5)$ & $34,2 \pm 5,9$ & $18,4 \pm 4,2$ & $14,4 \pm 3,0$ \\
\hline & Özel hastane & $54(13,8)$ & $35,4 \pm 7,9$ & $17,1 \pm 5,4$ & $14,9 \pm 3,7$ \\
\hline Test ve Anlamlılık & & & $\begin{array}{l}F=1,61 \\
p=0,18\end{array}$ & $\begin{array}{l}F=2,08 \\
p=0,10\end{array}$ & $\begin{array}{l}F=1,39 \\
p=0,24\end{array}$ \\
\hline \multirow[t]{2}{*}{ Sigara alışkanlığı } & $\begin{array}{l}\text { Evet } \\
\text { Hiç içmedim } \\
\text { Bu süreçte } \\
\text { bıraktım }\end{array}$ & $\begin{array}{l}76(19,5) \\
279(71,5) \\
9(2,3)\end{array}$ & $\begin{array}{l}34,2 \pm 7,1 \\
34,3 \pm 6,7 \\
26 \pm 12,8\end{array}$ & $\begin{array}{l}17,6 \pm 4,1 \\
17,1 \pm 4,6 \\
14,2 \pm 6,7\end{array}$ & $\begin{array}{l}14,4 \pm 3,5 \\
14,3 \pm 3,2 \\
10,6 \pm 5,2\end{array}$ \\
\hline & $\begin{array}{l}\text { Bu süreçten önce } \\
\text { bırakmıştım }\end{array}$ & $26(6,7)$ & $31,2 \pm 9,3$ & $18 \pm 4,2$ & $13,7 \pm 4,4$ \\
\hline Test ve Anlamlılık & & & $F=5,28, p=0,001$ & $\begin{array}{l}F=1,77 \\
p=0,15\end{array}$ & $\begin{array}{l}F=3,73 \\
p=0,01\end{array}$ \\
\hline $\begin{array}{l}\text { Bireyin kronik } \\
\text { hastalık durumu }\end{array}$ & $\begin{array}{l}\text { Evet } \\
\text { Hayır }\end{array}$ & $\begin{array}{l}46(11,8) \\
344(88,2)\end{array}$ & $\begin{array}{l}31,9 \pm 8,7 \\
34,2 \pm 7,0\end{array}$ & $\begin{array}{l}17,4 \pm 5,1 \\
17,2 \pm 4,5\end{array}$ & $\begin{array}{l}14,2 \pm 4,1 \\
14,2 \pm 3,3\end{array}$ \\
\hline Test ve Anlamlılık & & & $\begin{array}{l}t=-1,68 \\
p=0,09\end{array}$ & $\begin{array}{l}t=0,23, \\
p=0,81\end{array}$ & $\begin{array}{l}t=0,006 \\
p=0,99\end{array}$ \\
\hline $\begin{array}{l}\text { Ailede yaşlı ya da } \\
\text { kronik hastalık } \\
\text { varlığı }\end{array}$ & $\begin{array}{l}\text { Evet } \\
\text { Hayır }\end{array}$ & $\begin{array}{l}151(38,7) \\
239(61,3)\end{array}$ & $\begin{array}{l}33,41 \pm 8,11 \\
34,28 \pm 6,73\end{array}$ & $\begin{array}{l}17,21 \pm 4,55 \\
17,28 \pm 4,60\end{array}$ & $\begin{array}{l}14,15 \pm 3,84 \\
14,35 \pm 3,21\end{array}$ \\
\hline Test ve Anlamlılık & & & $\begin{array}{l}t=-1,15 \\
p=0,24\end{array}$ & $\begin{array}{l}t=-0,14 \\
p=0,88\end{array}$ & $\begin{array}{l}t=-0,54 \\
p=0,58\end{array}$ \\
\hline TOPLAM & & $390(100)$ & $33,94 \pm 7,30$ & $17,26 \pm 4,58$ & $14,27 \pm 3,46$ \\
\hline
\end{tabular}

Hemşirelerin pandemi sürecinde uyguladığı korunma yöntemleri incelendiğinde; \%87,7'sinin hasta ile temas öncesinde ellerini yıkadığı, \%94,1'inin aseptik işlemler öncesi ellerini yıkadığı, \%92,8'inin ellerini sık sık 20 saniye boyunca su ve sabunla yıkadığı, \%27,2'sinin gözle görünür kir olmadığı sürece sadece dezenfektan kullandığı, \%97,2'sinin hasta ile temas sonrasında ellerini yıkadığı, \%11,8'inin gözle görünür kir olduğu zaman ellerini yıkadığı, \%95,9'unun kirli eller ile burun, göz ve çevresine dokunmaktan kaçındığı, \%71'inin korona virüslü hastayla karşılaşma intimaline karşı sürekli koruyucu ekipman kullandığı, \%77,9'unun hastanede de sosyal mesafe kuralına uyduğu, \%14,6'sının önlem için profilaktik ilaç kullandığı ve $\% 97,7$ 'sinin formalarını sık sık yıkadığı belirlenmiştir (Tablo 3).

Hemşirelerin hasta ile temas öncesi ellerini yıkama tutumu ile Acil Durumda Çalışanların Öz Yeterlilik Ölçeği yetkinlik ve istek alt boyutu arasında anlamlı fark bulunmuştur $(p<0,05)$. Ayrıca aseptik işlemler öncesinde ellerini yıkama, elleri sık sık, en az 20 saniye süreyle su ve sabunla yıkama tutumu ve hastanede sosyal mesafe kuralına dikkat etme ile Acil Durumda Çalışanların Öz Yeterlilik Ölçeği yetkinlik alt boyutu arasındaki fark, istatistiksel olarak anlamlıdır $(\mathrm{p}<0,05)$ (Tablo 3).

Hasta ile temas öncesi ellerini yıkayan $(34,1 \pm 7,1)$ ve yıkamayan hemşirelerin $(36,4 \pm 5,5)$ yetkinlik ortalama puanı ellerini bazen yıkayan $(30,7 \pm 8,9)$ hemşirelerin yetkinlik puanından, istek alt boyutunda ise hasta ile temas öncesi ellerini yıkamayan $(20,8 \pm 4,7)$ hemşirelerin ortalama puanı yıkayan $(17,2 \pm 4,5)$ ve bazen yıkayan $(16,1 \pm 4,4)$ hemşirelerin ortalama puanından anlamlı derecede yüksektir $(p<0,05)$ (Tablo 3).

Aseptik işlemler öncesi ellerini yıkayan $(34,1 \pm 7,1)$ ve ellerini sık sık 20 saniye boyunca su ve sabunla yıkayan $(34,3 \pm 6,7)$ hemşirelerin yetkinlik puan ortalamaları aseptik işlemler öncesi ellerini yıkamayan $(30,8 \pm 9,3)$ ve ellerini sık sık 20 saniye boyunca su ve sabunla yıkamayan $(28,7 \pm 11,4)$ hemşirelerin puan ortalamalarından anlamlı derecede yüksek bulunmuştur( $p<0,05)$ (Tablo 3).

Hastane ortamında sosyal mesafe kuralına uyan $(34,3 \pm 7,2)$ ve bazen uyan $(33,3 \pm 6,6)$ hemşirelerin yetkinlik puan ortalaması sosyal mesafe kuralına uymayan $(29,6 \pm 9,0)$ hemşirelerin puan ortalamasından anlamlı derecede yüksek bulunmuştur $(p<0,05)$ (Tablo 3$)$. 
Tablo 3. Hemşirelerin koronavirüsten korunma yöntemleri ile acil durumda çalışanların öz yeterliliği arasındaki ilişki.

\begin{tabular}{|c|c|c|c|c|c|}
\hline MADDELER & & $n(\%)$ & YETKINLİK & ISTTEK & İLGí \\
\hline $\begin{array}{l}\text { Hasta ile temas öncesinde ellerimi } \\
\text { yıkarım }\end{array}$ & $\begin{array}{l}\text { Evet } \\
\text { Hayır } \\
\text { Bazen }\end{array}$ & $\begin{array}{l}342(87,7) \\
15(3,8) \\
33(8,5)\end{array}$ & $\begin{array}{l}34,1 \pm 7,1 \\
36,4 \pm 5,5 \\
30,7 \pm 8,9\end{array}$ & $\begin{array}{l}17,2 \pm 4,5 \\
20,8 \pm 4,7 \\
16,1 \pm 4,4\end{array}$ & $\begin{array}{l}24,4 \pm 7,5 \\
25,4 \pm 7,8 \\
23,9 \pm 7,8\end{array}$ \\
\hline Test ve Anlamlılık & & & $F=4,30, p=0,01$ & $F=5,59, p=0,004$ & $F=0,18, p=0,83$ \\
\hline $\begin{array}{l}\text { Aseptik işlemler öncesinde } \\
\text { ellerimi yıkarım }\end{array}$ & $\begin{array}{l}\text { Evet } \\
\text { Hayır }\end{array}$ & $\begin{array}{l}367(94,1) \\
23(5,9)\end{array}$ & $\begin{array}{l}34,1 \pm 7,1 \\
30,8 \pm 9,3\end{array}$ & $\begin{array}{l}17,2 \pm 4,4 \\
17,5 \pm 6,4\end{array}$ & $\begin{array}{l}24,4 \pm 7,6 \\
24,3 \pm 7,4\end{array}$ \\
\hline Test ve Anlamlılık & & & $\begin{array}{l}t=2,09 \\
p=0,03\end{array}$ & $t=-0,23, p=0,81$ & $\mathrm{t}=0,04, p=0,96$ \\
\hline $\begin{array}{l}\text { Ellerimi sık sık, en az } 20 \text { saniye } \\
\text { süreyle su ve sabunla yıkarım }\end{array}$ & $\begin{array}{l}\text { Evet } \\
\text { Hayır }\end{array}$ & $\begin{array}{l}362(92,8) \\
28(7,2)\end{array}$ & $\begin{array}{l}34,3 \pm 6,7 \\
28,7 \pm 11,4\end{array}$ & $\begin{array}{l}17,3 \pm 4,3 \\
16,0 \pm 6,8\end{array}$ & $\begin{array}{l}14,4 \pm 3,2 \\
12,5 \pm 5,6\end{array}$ \\
\hline Test ve Anlamlılık & & & $\begin{array}{l}t=2,54 \\
p=0,01\end{array}$ & $t=1,01, p=0,32$ & $t=1,78, p=0,08$ \\
\hline $\begin{array}{l}\text { Gözle görülür kir olmadığı sürece } \\
\text { sadece el dezenfektanı kullanırım }\end{array}$ & $\begin{array}{l}\text { Evet } \\
\text { Hayır } \\
\text { Bazen }\end{array}$ & $\begin{array}{l}106(27,2) \\
174(44,6) \\
110(28,2)\end{array}$ & $\begin{array}{l}34,5 \pm 7,78 \\
33,7 \pm 7,43 \\
33,7 \pm 6,62\end{array}$ & $\begin{array}{l}17,4 \pm 5,0 \\
16,9 \pm 4,7 \\
17,5 \pm 3,7\end{array}$ & $\begin{array}{l}14,5 \pm 3,5 \\
17,2 \pm 3,5 \\
14,0 \pm 3,3\end{array}$ \\
\hline Test ve Anlamlılık & & & $\begin{array}{l}F=0,41 \\
p=0,66\end{array}$ & $\mathrm{~F}=0,85, \mathrm{p}=0,42$ & $\mathrm{~F}=0,54, \mathrm{p}=0,57$ \\
\hline $\begin{array}{l}\text { Hasta ile temas sonrasında } \\
\text { ellerimi yıkarım }\end{array}$ & $\begin{array}{l}\text { Evet } \\
\text { Hayır }\end{array}$ & $\begin{array}{l}379(97,2) \\
11(2,8)\end{array}$ & $\begin{array}{l}33,9 \pm 7,1 \\
32,7 \pm 11,0\end{array}$ & $\begin{array}{l}17,2 \pm 4,4 \\
18,9 \pm 7,0\end{array}$ & $\begin{array}{l}14,2 \pm 3,3 \\
14 \pm 5,6\end{array}$ \\
\hline Test ve Anlamlılık & & & $\begin{array}{l}t=0,37 \\
p=0,71\end{array}$ & $t=-0,79, p=0,44$ & $t=0,16, p=0,86$ \\
\hline $\begin{array}{l}\text { Sadece gözle görülür kir olduğu } \\
\text { zaman ellerimi yıkarım }\end{array}$ & $\begin{array}{l}\text { Evet } \\
\text { Hayır } \\
\text { Bazen }\end{array}$ & $\begin{array}{l}46(11,8) \\
294(75,4) \\
50(12,8)\end{array}$ & $\begin{array}{l}33,1 \pm 10,0 \\
33,9 \pm 6,6 \\
34,9 \pm 7,8\end{array}$ & $\begin{array}{l}17,7 \pm 6,5 \\
17,0 \pm 4,1 \\
17,8 \pm 4,9\end{array}$ & $\begin{array}{l}14,2 \pm 4,5 \\
14,1 \pm 3,2 \\
14,8 \pm 3,5\end{array}$ \\
\hline Test ve Anlamlılık & & & $\begin{array}{l}F=0,71 \\
p=0,49\end{array}$ & $\mathrm{~F}=0,81, \mathrm{p}=0,44$ & $\mathrm{~F}=0,70, \mathrm{p}=0,49$ \\
\hline $\begin{array}{l}\text { Kirli eller ile ağız, burun, göz ve } \\
\text { çevresine dokunmaktan kaçınırım }\end{array}$ & $\begin{array}{l}\text { Evet } \\
\text { Hayır }\end{array}$ & $\begin{array}{l}374(95,9) \\
16(4,1)\end{array}$ & $\begin{array}{l}34,1 \pm 6,9 \\
30,3 \pm 12,9\end{array}$ & $\begin{array}{l}17,2 \pm 4,4 \\
17,5 \pm 7,1\end{array}$ & $\begin{array}{l}14,3 \pm 3,3 \\
12,5 \pm 5,5\end{array}$ \\
\hline Test ve Anlamlılık & & & $\begin{array}{l}t=1,16 \\
p=0,26\end{array}$ & $t=-0,17, p=0,86$ & $t=1,33, p=0,20$ \\
\hline $\begin{array}{l}\text { Koronavirüslü hastayla } \\
\text { karşılaşma ihtimaline karşı sürekli } \\
\text { kişisel koruyucu ekipmanlar } \\
\text { kullanırım }\end{array}$ & $\begin{array}{l}\text { Evet } \\
\text { Hayır } \\
\text { Bazen }\end{array}$ & $\begin{array}{l}277(71) \\
39(10) \\
74(19)\end{array}$ & $\begin{array}{l}34,0 \pm 7,6 \\
33,6 \pm 7,1 \\
33,8 \pm 6,0\end{array}$ & $\begin{array}{l}17,1 \pm 4,7 \\
17,4 \pm 4,0 \\
17,4 \pm 4,1\end{array}$ & $\begin{array}{l}14,2 \pm 3,4 \\
14,5 \pm 3,8 \\
14,3 \pm 3,2\end{array}$ \\
\hline Test ve Anlamlılık & & & $\begin{array}{l}F=0,05 \\
p=0,94\end{array}$ & $\mathrm{~F}=0,09, \mathrm{p}=0,91$ & $\mathrm{~F}=0,11, \mathrm{p}=0,89$ \\
\hline $\begin{array}{l}\text { Hastanede sosyal mesafe kuralına } \\
\text { dikkat ederim }\end{array}$ & $\begin{array}{l}\text { Evet } \\
\text { Hayır } \\
\text { Bazen }\end{array}$ & $\begin{array}{l}304(77,9) \\
15(3,8) \\
71(18,2)\end{array}$ & $\begin{array}{l}34,3 \pm 7,2 \\
29,6 \pm 9,0 \\
33,3 \pm 6,6\end{array}$ & $\begin{array}{l}17,1 \pm 4,5 \\
18,7 \pm 4,6 \\
17,5 \pm 4,5\end{array}$ & $\begin{array}{l}14,4 \pm 3,4 \\
13,2 \pm 4,1 \\
13,9 \pm 3,5\end{array}$ \\
\hline Test ve Anlamlılık & & & $\begin{array}{l}F=3,34 \\
p=0,03\end{array}$ & $\mathrm{~F}=1,01, \mathrm{p}=0,36$ & $F=1,31, p=0,26$ \\
\hline $\begin{array}{l}\text { Önlem için profilaktik ilaç } \\
\text { (antibiyotik, antiviral, vitamin ilacı, } \\
\text { sıtma ilaçları vs) kullanırım }\end{array}$ & $\begin{array}{l}\text { Evet } \\
\text { Hayır } \\
\text { Bazen }\end{array}$ & $\begin{array}{c}57(14,6) \\
283(72,6) \\
50(12,8)\end{array}$ & $\begin{array}{l}32,9 \pm 9,9 \\
34,0 \pm 6,7 \\
34,7 \pm 6,7\end{array}$ & $\begin{array}{l}17,7 \pm 6,1 \\
17,0 \pm 4,2 \\
18,0 \pm 4\end{array}$ & $\begin{array}{l}13,7 \pm 4,7 \\
14,2 \pm 3,1 \\
14,8 \pm 3,1\end{array}$ \\
\hline Test ve Anlamlılık & & & $\begin{array}{l}F=0,83 \\
p=0,43\end{array}$ & $\mathrm{~F}=1,31, \mathrm{p}=0,26$ & $\mathrm{~F}=1,50, \mathrm{p}=0,22$ \\
\hline Formalarımı sık sık yıkarım & $\begin{array}{l}\text { Evet } \\
\text { Hayır }\end{array}$ & $\begin{array}{l}381(97,7) \\
9(2,3)\end{array}$ & $\begin{array}{l}33,9 \pm 7,3 \\
33,2 \pm 6,3\end{array}$ & $\begin{array}{l}17,1 \pm 4,5 \\
20,3 \pm 6,9\end{array}$ & $\begin{array}{l}14,3 \pm 3,4 \\
13,2 \pm 4,3\end{array}$ \\
\hline Test ve Anlamlılık & & & $\begin{array}{l}t=0,30 \\
p=0,76\end{array}$ & $t=-1,35, p=0,21$ & $t=0,92, p=0,35$ \\
\hline
\end{tabular}

Hemşirelerin \%84,6'nın sosyal izolasyon kurallarına uyduğu, \%95,6'sının işe gitmek dışında gerekmedikçe evden dışarı çıkmadığı, \%88,2'sinin en az bir metre mesafe kuralına dikkat ettiği, $\% 86,9$ 'unun evine misafir kabul etmediği, \%85,9'unun market alışverişini haftada bir olacak şekilde planladığı, \%80,5'inin ailesi ve 65 yaş üstü yakınları ile görüşmediği ve \%68,7'sinin toplu taşıma araçlarını kullanmadığı belirlenmiştir (Tablo 4).

Hemşirelerin \%35,1'i ayrı yaşamakta olup, aile üyeleri ile yaşayan bireylerin $\% 52,1^{\prime} i$ az (1-2 uygulama) dikkat ederken; $\% 45,4$ 'ü orta (3-4 
uygulama), \%2,6'sı yüksek düzeyde (5 uygulama) dikkat etmektedir (Tablo 4). Çalışmaya katılan hemşirelerin \%23,3'ü çocuğu ile iletişimi konusunda olumsuz duygulara sahip iken; çoğunluğunun çocuğu bulunmamaktadır (Tablo4). Çalışmaya katılan hemşirelerin \%36,1'inde bu süreçte eşleri ile ilişkisinde bazı olumsuzluklar yaşadıkları tespit edilirken; 26,7'si bu süreçte eşi tarafından desteklenmiştir (Tablo 4).

Tablo 4. Hemşirelerin sosyal izolasyon kurallarına uyma durumları.

\begin{tabular}{|c|c|c|c|}
\hline \multicolumn{2}{|l|}{ MADDE } & $\mathbf{n}$ & $\%$ \\
\hline \multicolumn{2}{|c|}{ İşe gitmek dışında gerekmedikçe evden dışarı çıkmıyorum. } & 373 & 95,6 \\
\hline \multicolumn{2}{|c|}{ En az bir metre mesafe kuralına dikkat ediyorum. } & 344 & 88,2 \\
\hline \multicolumn{2}{|c|}{ Evime misafir kabul etmiyorum. } & 339 & 86,9 \\
\hline \multicolumn{2}{|c|}{ Market alışverişini haftada bir olacak şekilde planlıyorum. } & 335 & 85,9 \\
\hline \multicolumn{2}{|c|}{ Ailemle ve 65 yaş üstü yakınlarım ile zorunlu olmadıkça görüşmüyorum. } & 314 & 80,5 \\
\hline \multicolumn{2}{|c|}{ Toplu taşıma araçlarını kullanmıyorum. } & 268 & 68,7 \\
\hline \multicolumn{2}{|c|}{ Mesai sonrası eve gelir gelmez banyo yapıyorum } & 233 & 59,7 \\
\hline \multicolumn{2}{|c|}{ Mesai sonrası eve gelir gelmez kıyafetlerimi çıkarıyorum ve yıkıyorum } & 231 & 59,2 \\
\hline \multicolumn{2}{|c|}{ Formamı diğer kıyafetlerle asla yıkamıyorum } & 180 & 45,9 \\
\hline \multicolumn{2}{|c|}{ Ailemle ayrı yaşıyorum } & 137 & 35,1 \\
\hline \multicolumn{2}{|c|}{ Ev içerisinde kendimi diğer aile üyelerinden izole ediyorum } & 105 & 26,9 \\
\hline \multicolumn{2}{|c|}{ Sosyal izolasyon kurallarından hiçbirini uygulamıyorum. } & 17 & 4,4 \\
\hline \multicolumn{2}{|c|}{ ÇOCUĞUM YOK } & 242 & 62,1 \\
\hline & Çocuğumla ilişkimde değişiklik yaşadım. & 107 & 72,3 \\
\hline ÇOCUĞU & Salgın sürecinde çocuğumla temas etmemeye çalışıyorum. & 75 & 50,6 \\
\hline \multirow[t]{3}{*}{ OLANLAR } & $\begin{array}{l}\text { Salgın sürecinde çocuğumla yeterince ilgilenemediğimi } \\
\text { düşünüyorum. }\end{array}$ & 70 & 47,2 \\
\hline & Çocuğum ile birlikte yaşamıyorum. & 23 & 15,5 \\
\hline & Çocuğuma iyi bir ebeveyn olmadığımı düşünüyorum. & 21 & 14,1 \\
\hline \multicolumn{2}{|c|}{ EVLí DEĞíLIM } & 225 & 57,7 \\
\hline \multirow{8}{*}{$\begin{array}{l}\text { EVLí } \\
\text { OLANLAR }\end{array}$} & Eşimle ilişkimde değişiklik yaşadım. & 111 & 67,3 \\
\hline & Eşim ile birbirimize daha az vakit ayırdık. & 63 & 38,1 \\
\hline & Eşim bu süreçte beni duygusal olarak daha fazla destekledi. & 54 & 32,7 \\
\hline & Eşim bu süreçte çocuklar ile daha fazla ilgilendi. & 50 & 30,3 \\
\hline & $\begin{array}{l}\text { Eşime bulaştırma korkusu nedeniyle odalarımızı ve diğer ortak } \\
\text { kullanım alanlarını ayırdık. }\end{array}$ & 45 & 27,2 \\
\hline & Rol çatışması yaşamaya başladık. & 16 & 9,6 \\
\hline & Eşime yük olduğumu düşünüyorum. & 12 & 7,2 \\
\hline & Eşim bu süreçte hiçbir şekilde benimle ve çocuklarımla ilgilenmedi. & 5 & 3 \\
\hline
\end{tabular}

Çalışmaya katılan hemşirelerin duygu durumları gelecekten umutludur (Tablo 5). değerlendirildiğinde \%63,8'i kaygılı iken, \%33,3'ü

Tablo 5. Hemşirelerin sosyal izolasyon kurallarına uyma durumları.

\begin{tabular}{lcc}
\hline & $\mathbf{n}$ & $\%$ \\
\hline Kaygılı & 249 & 63,8 \\
Korku içinde & 112 & 28,7 \\
Güvensiz & 112 & 28,7 \\
Çaresiz & 76 & 19,5 \\
Gelecekten umutlu & 130 & 33,3 \\
Diğer & 1 & 0,2 \\
\hline
\end{tabular}




\section{TARTIŞMA}

COVID-19 salgına karşı verilen mücadelede tüm sağlık çalışanları gibi hemşireler de ön saflarda yer almaktadırlar ve salgına yol açan patojenle (bu son örnekte COVID-19) enfekte olma riskinde en riskli gruplardan biridir. Bu nedenle hemşirelerin COVID-19 hastalığının bulaş yolu ve hastalıktan korunmaya yönelik bilgi tutum ve beklentileri ile yeterli ve sürdürülebilir insan kaynağının sağlanması, salgını önleme ve kontrol çalışmalarının temelini oluşturmaktadır (Duygulu ve ark., 2020). Upadhyaya ve ark. yaptığı çalışmada sağlık çalışanlarının COVID-19 hakkındaki bilgi düzeylerinin arttıılmasının, hükümetin COVID-19'a karşı aldığı tedbirlerin doğru algılanmasının ve sağlık çalışanlarını korumaya yönelik gerekli tedbirlerin alınmasının sağıı çalışanlarının çalışma isteğini arttırmada önemli unsurlar olduğu belirlenmiştir (Upadhyaya ve ark., 2020). Lam ve ark. yaptığı nitel araştırmada hemşirelerin COVID-19'un neden olduğu belirsiz çalışma durumuna karşı intiyatı oldukları, uygulama ve görevlerindeki değişikliklere adaptasyon yeteneklerinin de yüksek olduğu belirlenmiştir (Lam ve ark., 2020). Araştırmamızda hemşirelerin yetkinlik, istek ve ilgi düzeylerinin oldukça iyi olduğu tespit edilmiştir. Bu bulgular, hemşirelerin bir halk sağığı acil durumunun üstesinden gelmek için gerekli karar verme ve problem çözme becerilerini edinmelerine ve geliştirmelerine olanak tanıyan eğitim ve öğretim programlarına duyulan intiyacın ne denli önemli olduğunu göstermektedir. Bahsedilen eğitimlerin hemşirelerin mesleklerine dair bilimsel bilgi dağarcığına katkı sağladığı, hemşirelerin mesleklerine dair profesyonel bakış açısıyla elde ettikleri bilgiyi harmanlayarak acil durum statüsünde olan COVID-19 pandemisiyle mücadeleye hazır olduklarını göstermesi açısından dikkat çekicidir.

Hemşirelerin COVID-19'a karşı sergiledikleri tutumları inceleyen çalışma sonuçları, genel olarak hemşirelerin çoğunluğunun koruyucu ve önleyici tedbirler arasında yer alan maske takma, koruyucu kıyafetler giyme, el hijyeni ve sosyal mesafeyi korumaya yönelik olumlu bir tutum içerisinde olduğunu raporlamıştır (Tadesse, Gebrewahd ve Demoz, 2020; Maleki, Najafi, Farhadive ark., 2020; Alwani, Majeed, Hirwani ve ark., 2020).Yapılan bu çalışmada da hemşirelerin sosyal yaşam ve hastane ortamında COVID19 'dan korunmak için aldıkları önlemlere bakıldığında; çoğunluğunun hasta ile temas öncesi ve sonrası, aseptik işlemler öncesi ellerini yıkadığı, el yıkama işlemini en az 20 saniye su ve sabunla yaptıkları, kirli eller ile göz ve çevresine dokunmaktan kaçındıkları, sosyal mesafeye dikkat ettikleri ve formalarını sık sık yıkadıkları saptanarak, salgınla mücadelede olumlu bir tutum sergiledikleri görülmüştür. Bu bulgular, hemşirelerin salgından korunmaya yönelik bilgi düzeylerinin yeterli olduğu ve bu bilgiyi davranışa dönüştürerek COVID-19'a yakalanma risklerini düşürmeye çalıştıkları şeklinde yorumlanabilir.

Hemşirelerin acil durumlardaki özyeterliliklerinin incelendiği çalışmalara bakıldığında; Xiong ve ark. COVID-19 sürecinde yaptığı çalışmada hemşirelerin öz yeterlik puan ortalamasını düşük bulunurken, $\mathrm{Hu}$ ve ark. acil durum hemşirelerinin öz yeterlilik puanlarının ortalamanın üzerinde olduğunu belirlemiştir (Xiong ve ark., 2020; Hu ve ark., 2018). Yapılan bu çalışmada ise, hemşirelerin acil durumlarda çalışabilecek öz yeterliliğe sahip oldukları tespit edilmiştir. Çalışma sonucu elde edilen bulgular doğrultusunda hemşirelerin; COVID-19 hastalığını acil bir durum olarak gördüğü, salgınla mücadelede öz yeterliliklerinin yüksek düzeyde olduğu, salgınla mücadelede korunma yöntemlerini daha etkin bir şekilde uygulayarak hastalığın yayılmasını engellemeye çalıştıkları belirlenmiştir. Bu durumun ülkemizde Sağlık Bakanlığı tarafından yapılan bu eğitimlerin hemşireler için yararlı etkileri olduğunu düşündürmektedir.

Çalışmaya katılan hemşirelerin; \%71,5'i hayatı boyunca hiç sigara içmediği, sigara içenlerin ise $\% 2,3$ 'ünün bu süreçte bıraktığı tespit edilmiştir. Maleki ve arkadaşlarının (2020) COVID-19'a yönelik sağlık çalışanlarının bilgi, tutum ve davranışlarını incelediği çalışmada genel olarak sağlık çalışanlarının ve özellikle hemşirelerin \%3,1'inin bu süreçte sigara içmekten sakındığı bildirilmiştir (Maleki ve ark., 2020). Elde ettiğimiz ve literatürle paralel olan bu bulgu, sağlık çalışanları arasında ve toplum içinde akut bir problem olarak görülen COVID-19 ile mücadelede olumlu sağlık davranışlarının etkili olduğunu düşündürmektedir. Aynı zamanda Patanavanich ve Glantz (2020)'ın sigara ve koronavirüs arasındaki ilişkiyi değerlendirmek amacıyla yaptığı meta-analiz çalışmasıda; sigaranın COVID19 'un ilerlemesinde risk faktörü olduğu ve hastalığın sigara içenlerde içmeyenlere göre daha hızlı bir şekilde ilerlediği bulunmuştur. Hemşirelerin de bu süreçte risk faktörü olan sigaradan uzak durmaları, sadece bakımını ve tedavisini yaptıkları hastaların hayatında değil, kendi hayatlarında da sağlıklı yaşam biçimi davranışları geliştirmeye çalıştıklarının göstergesidir (Patanavanich ve ark., 2020). Yapılan bu çalışmada COVID-19 sürecinde sigarayı bırakan hemşirelerin Acil 
Durumda Çalışanların Öz Yeterlilik Ölçeği Yetkinlik ve İlgi alt boyutlarından aldıkları puanların diğer gruplara göre daha düşük olduğu belirlenmiştir. Hemşirelerin Yetkinlik ve İstek alt boyutlarından düşük puan almaları salgından korunmaya yönelik sergilemiş oldukları bu tutumun bireysel ve ailesel sağılılarını korumaya yönelik yapıldığını düşündürmektedir.

Pandemi sürecinde sağlık çalışanları enfekte olmaktan, aile ve sevdiklerini enfekte etmekten, nihayetinde, kendi ölümlerinden ve sevdiklerinin ölümlerinden korkmaktadır (Blanco-Donoso, Moreno-Jiménez,

Gálvez-Herrerve ark.,2020).Yapılan çalışmalar incelendiğinde COVID-19 şüphelisi hastayla karşılaşan ya da bu hastalara bakım veren hemşirelerin enfekte olmaktan ve hastalığı ailelerine bulaştırmaktan korktukları belirtilmiştir (Huynh, Nguyen, Vo ve ark., 2020; Schwerdtle, Connell, Lee ve ark., 2020).Maleki ve ark. (2020) yaptığı çalışmada, hemşirelerin büyük çoğunluğunun endişeli olduğu, hastalığı kendisine ve ailesinde bulaştırmaktan korktukları belirtilmiştir (Maleki ve ark., 2020).Bu çalışmada da hemşirelerin yarısından fazlası ailesi ile birlikte yaşamaktadır. Kendilerini ve sevdiklerini korumak için alınan önlemler doğrultusunda çalışmadaki hemşirelerin çoğunluğunun; pandemi sürecinde alınan korunma yöntemlerine uydukları ve azımsanmayacak bir grubun ise formalarını diğer kıyafetleriyle birlikte yıkadığı belirlenmiştir. Bu konuda Türk Hemşireler Derneği'nin "Formanı işte bırak, sen yokken hastanede o beklesin." sloganının forma hijyeni konusunda daha fazla dikkate alınması gerektiği ifade edilebilir (THD, 2020).COVID-19 hastalığını kendisine ve ailesine bulaştırmaktan kaçınmak adına hastane ve sosyal ortamda birçok korunma yönetimini etkili bir şekilde uygulayan hemşirelerin bu tutumlarını daha fazla sürdürmeleri konusunda desteklenmesi gerekmektedir.

Pandemi döneminde bulaş korkusu ve uzun çalışma saatleri nedenleriyle hemşireler yaşam alanlarından ve ailelerinden ayrı kalmayı yeğlemekte, eş ve çocuklarıyla fiziksel temas olmaksızın telefon yoluyla iletişimlerini sürdürmektedirler. $\mathrm{Bu}$ nedenle, hemşirelerin algıladıkları duygusal ve sosyal destek azalabilmektedir (Enli Tuncay ve Koyuncu, 2020). Özellikle çocuğu olan sağlık çalışanları bu izolasyon durumunu çocuklarına ifade etmekte zorlanmıştır. Salgın nedeniyle okulların uzaktan eğitim sistemine geçmesi, kreşlerin kapanması ile çocukların ev ortamında geçirdiği zamanın artmasına neden olmuş, bu durumda sağlık çalışanları için çocuk bakımı önemli bir yük haline gelmiştir (Güvenç ve ark., 2020). Bu çalışmada da hemşirelerin bir kısmı çocuğuyla yeterince ilgilenemediğini ve süreçten dolayı çocuğuyla fazla temasa geçmediğini ifade ederek çocuğu ile iletişimi konusunda olumsuz duygulara sahip olduğunu belirtmiştir. Çocukların bakımına ve eğitimine destek olan kreşlerin kapanması, izolasyon halindeyken beraber geçen zamanın daha az olması, çocukların uzaktan eğitim sürecinde intiyaç duydukları ilgi ve bakımın artması gibi faktörler sağlık çalışanlarının kendilerini ev yaşantısı içerisinde yetersiz olarak algılamalarına ve rol çatışmalarına neden olmuştur (Güvenç ve Baltacı, 2020). Bu bulgulardan hareketle, pandemi sürecinin hemşirelerde de aile ve özel yaşamı olumsuz yönde etkilediği, özellikle çocuk bakımı ve çocukların eğitim sürecinde yürütülmesi gereken sorumluluklar konusunda zorlayıcı olduğu ifade edilebilir.

Pandemi nedeniyle birçok ülke alarm durumuna geçmiştir. Birçok acil durumla karşı karşıya kalan sağlık çalışanları salgınla mücadelede ön saflarda yer almaktadır. Bu sürecin sağlık çalışanları üzerindeki psiko-duygusal etkisi, duygusal profili, davranışsal özellikleri ve genel kişiliğin çeşitli yönlerini etkileyen, zihinsel refahı potansiyel olarak tehlikeye atabilecek çeşitli faktörleri içermektedir. Stres düzeyleri, korku, depresyon ve ilgili başa çıkma mekanizmaları, çaresizlik duyguları ve bunların nasıl şekillendiği, iş yüküne bağıı tükenmişlik ve kaygı, bu bağlamda endişe verici konulardır. Bu acil durumla mücadele eden sağlık çalışanlarının kötüleşen psiko-duygusal durumla da başa çıkması gerektiği bilinmektedir (Karampelias, Karonis ve Psaroudi, 2020). Bu çalışmada ise; hemşirelerin \%63,8'inin kaygllı, \%66,7'sinin gelecekten umutlu olmadığı belirlenmiştir. Çalışma bulgularımıza paralel şekilde, Çin'de sağlık çalışanları ile yapılan çok merkezli bir çalışmada, depresyon, anksiyete ve stres belirtilerinin oldukça fazla olduğu bulunmuştur. Türk Hemşireler Derneği'nin yaptığı çalışmada da hemşirelerin çoğunluğu; endişe, korku ve tükenmişlik duygularını yaşadığını ifade etmiştir (THD, 2020).Bu bağlamda, pandemi süreci ve sonrasında hemşirelerin psikososyal sağlık durumlarını inceleyen prospektif çalışmalara gereksinim duyulmaktadır.

\section{Araştırmanın Güçlü Yönleri Ve Sınırılıkları}

COVID-19 sadece hastalar için değil, aynı zamanda onlara bakım veren ve krizin yükünü taşıyan sağlık profesyonelleri için de ciddi olabilmektedir. Sağlık ekibinin çoğunluğunu oluşturan ve bu süreçte anahtar rolde olan hemşirelerin COVID-19 sürecindeki acil durum öz-yeterlilikleri, yaşam alanlarındaki değişiklikler, sosyal izolasyon kurallarına uyma 
durumları ve bu süreçteki ruh halleri hem kendi sağlıkları hem de bakım gereksinimi olan insanların sağlıkları üzerinde oldukça etkilidir. Yapılan çalışma ile bu parametrelerin değerlendirilmesi literatüre önemli katlı sağlamıştır. Araştırma verilerinin toplanmasında katılımcılara online ortamda ulaşmada güçlük yaşanması, online ağları olmayan hemşirelerin görüşlerine ulaşılamaması çalışmanın sınırlılıkları arasında sayılmaktadır.

\section{Etik Onay}

Online anket yolu ile uygulanan araştırma için; Sağlık Bakanlığı'ndan “19.05.2020 tarihli 2020-0515T22_05_19 sayılı" ve ilgili üniversitenin etik kurulundan "30.04.2020 tarihli 2020/142 sayılı" etik kurul kararı ile onay alınmıştır. Araştırma Helsinki Bildirgesi ilkelerine uygun olarak yürütülmüştür.

\section{Araştırmacıların Katkı Oranı}

Araştırmanın fikri Zeynep Güngörmüş tarafından belirlenmiş olup, veri toplama süreci, analiz ve yorumu, literatür taraması, makale yazımı tüm araştırmalar tarafından yapılmıştır. Sonuçlara ulaşılmasını sağlayacak yöntemin tasarlaması ve planlanması, çalışmanın yürütülmesini organize etmek, ilerlemesini gözetmek ve sorumluluğunu almak, çalışmanın teslim edilmesinden önce, dil ve yazınsal düzeltmelerden bağımsız olarak, bilimsel anlamda çalışmanın yeniden değerlendirmesi Zeynep Güngörmüş ve Çiğdem Aksu tarafından yapılmıştır.

\section{Çıkar Çatışması Beyanı}

Yazarların herhangi bir çıkara dayalı ilişkisi yoktur.

\section{Destek/Teşekkür}

Çalışmayı maddi olarak destekleyen kişi/kuruluş yoktur

\section{Kaynaklar}

Alwani, S. S., Majeed, M. M., Ramzan, Z., Rauf, S., Syed, M. S., Shah, S. H., et al. (2020). Evaluation of knowledge, practices, attitude, and anxiety of nurses towards COVID-19 during the current outbreak in Karachi, Pakistan. Pakistan Journal of Public Health, 10(2), 8290.https://doi.org/10.32413/pjph.v10i2.601

Blanco-Donoso, L. M., Garrosa, E., Moreno-Jiménez, J., Gálvez-Herrer, M., \&Moreno-Jiménez, B. (2020). Occupational psychosocial risks of health professionals in the face of the crisis produced by the COVID-19: from the identification of these risks to immediate action. IJNS Advances, 2,100003. https://doi.org/10.1016/j.jijnsa.2020.100003

Duygulu, S., Açıl, S. B., Özdemir, E. K., \& Erdat, Y. (2020). Covid-19 salgını: yönetici hemşirelerin rol ve sorumlulukları. Hacettepe Üniversitesi Hemşirelik
Fakültesi Dergisi, 7(Özel Sayı), 3446.https://doi.org/10.31125/hunhemsire.776215

Enli Tuncay, E., Koyuncu, E., \& Özel, Ş. (2020). Pandemilerde sağlık çalışanlarının psikososyal sağlığını etkileyen koruyucu ve risk faktörlerine ilişkin bir derleme. Ankara Med J, 20(2), 488-504. https://doi.org/10.5505/amj.2020.02418

Güvenç, R.,\&Baltacı, E. (2020). COVID-19 ve sağlık çalışanlarının ruh sağlığı. Türk Tabipleri Birliği COVID-19 İzleme Kurulu (Eds.), Türk Tabipler Birliği COVID-19 pandemisi altıncı ay değerlendirme raporu (pp. 349-354). Retrieved from the Web November 14, 2020. https://www.ttb.org.tr/kutuphane/covid19-rapor_6.pdf

Ho, C. S., Chee, C. Y., \&Ho, R. C. (2020). Mental Health strategies to combat the psychological impact of COVID-19 beyond paranoia and panic. Ann Acad Med Singapore, 49(1), 1-3.

Hu, S. H.,Yu, Y. M., Chang, W. Y., \& Lin, Y. K. (2018). Social support and factors associated with self-efficacy among acute-care nurse practitioners. J Clin Nurs, 27(3-4), 876882.https://doi.org/10.1111/jocn.14129

Huynh, G., Nguyen, T. N. H., Vo, K. N., \& Pham, L. A. (2020). Knowledge and attitude toward COVID-19 among health care workers at District 2 Hospital, Ho Chi Minh City. AsianPac J Trop Dis, 13(6), 260-265. https://doi.org/10.4103/1995-7645.280396

Karampelias, V., Karonis, D., \&Psaroudi, V. (2020). The psychoemotional impact of COVID-19 on surgical staff working in emergency departments. Eur J Trauma Emerg Surg, 46, 747-749. https://doi.org/10.1007/s00068-020-01411-3

Lam, S. K., Kwong, E. W., Hung, M. S., \& Chien, W. T. (2020). Investigating the strategies adopted by emergency nurses to address uncertainty and change in the event of emerging infectious diseases: a grounded theory study. Int. J. Environ. Res. Public Health, 17(7), 2490.https://doi.org/10.3390/ijerph17072490

Ludwig, S.,\&Zarbock, A. (2020). Coronaviruses and SARS-CoV2: a brief overview. Anesth Analg,131(1), 93-96. https://doi.org/10.1213/ANE.0000000000004845

Maleki, S., Najafi, F., Farhadi, K., Fakhri, M., Hosseini, F., \&Naderi, M. (2020). Knowledge, attitude and behavior of healthcare workers in the prevention of COVID-19. Res Sq, 21, 203.https://doi.org/10.21203/rs.3.rs-23113/v1

Patanavanich, R., \&Glantz, S. A. (2020). Smoking is associated with COVID-19 progression: a meta-analysis. Nicotine Tob Res, 22(9), 1653-1656. https://doi.org/10.1093/ntr/ntaa082/5835834

Schaeffer, R. L., Mendenhall, W., \& Ott, L.(1990). Elementary Survey Sampling. (4. ed.). California: Belmont: DuxburyPress.

Schwerdtle, P. N., Connell, C. J., Lee, S., Plummer, V., Russo, P. L., Endacott, R., et al. (2020). Nurse expertise: a critical resource in the COVID-19 pandemic response. Ann Glob Health, 86(1), 49-53. https://doi.org/10.5334/aogh.2898

Tadesse, D. B., Gebrewahd, G. T., \& Demoz, G. T. (2020). Knowledge, attitude, practice and psychological response toward COVID-19 among nurses during the COVID-19 outbreak in northern Ethiopia, 2020. New Microbesand New Infections, 100787.https://doi.org/10.1016/j.nmni.2020.100787

T.C. Sağlık Bakanlığı Halk Sağlığı Genel Müdürlüğü. (14 Nisan 2020). COVID-19 (SARS-CoV2 Enfeksiyonu) rehberi bilim kurulu çalışması. Ankara: T.C. Sağlık Bakanlığı. Retrieved from the Web November 14, 2020. 
https://dosyamerkez.saglik.gov.tr/Eklenti/37175,covid19rehberipdf.pdf?0

T.C. Sağlık Bakanlığı Sağlık Hizmetleri Genel Müdürlüğü. "Türkiye'de genelinde görev yapan doktor ve hemşire sayılarına ilişkin" konulu yazııı soru önergesi cevabı. Ankara: T.C. Sağlık Bakanlığı. Retrieved from the Web April 26, 2021. https://www2.tbmm.gov.tr/d27/7/722769sgc.pdf

ThinkTech (2020). COVID-19 ile mücadelede örnek ülkeler. Retrieved from the Web November 14, 2020. https://thinktech.stm.com.tr/uploads/raporlar/pdf/6420 20135824738_stm_blog_covid_19_ile_mucadelede_o rnek_ulkeler.pdf

Türk Hemşireler Derneği (THD). (2020). COVID-19 pandemi sürecinde hemşirelerin durumu. COVID-19 2. Özel Sayısı. Retrieved from the Web November 2, 2020. http://www.thder.org.tr/uploads/files/covid19-2ozel.pdf

Türkiye İstatistik Kurumu. (2019). İstatistikler, Sağlık ve Sosyal Koruma. Sağlık Personeli Sayısı. Retrieved from the Web April 27, 2021. www.tuik.gov.tr

Upadhyaya, D. P., Paudel, R., Bromberg, D. J., Acharya, D., Khoshnood, K., Lee, K., et al. (2020). Frontline healthcare workers' knowledge and perception of COVID-19, and willingness to work during the pandemic in Nepal. Healthcare, 8(4), 554. https://doi.org/10.3390/healthcare8040554

World Health Organization (WHO). (2020a). Koronavirus hastalığı (COVID-19) salgını: sağlık çalışanlarının hakları, rolleri ve sorumlulukları sağlık çalışanlarının sağlığı ve güvenliği. Retrieved from the Web November $1,2020$. https://www.ttb.org.tr/userfiles/files/dso-saglikcalisanlarinin-sagligi.pdf

World Health Organization (WHO). (2020b). COVID-19
Public Health Emergency of International Concern (PHEIC) global research and innovation forum. Retrieved from the Web Novemr $1,2020$. https://www.who.int/publications/m/item/covid-19-publichealth-emergency-of-international-concern-(pheic)-globalresearch-and-innovation-forum

Xiang, Y. T., Yang, Y., Li, W., Zhang, L., Zhang, Q., Cheung, T., et al. (2020). Timely mental healthcare for the 2019 novel coronavirus outbreak is urgently needed. Lancet Psychiatry, 7(3), 228-229.https://doi.org/10.1016/S22150366(20)30046-8

Xiong, H., Yi, S., \& Lin, Y. (2020). The psychological status and self-efficacy of nurses during COVID-19 outbreak: a crosssectional survey. INQUIRY: The Journal of Health Care Organization, Provision, and Financing, 57, 1-6. https://doi.org/10.1177/0046958020957114

Yalçın, F. (2018). Acil Durumlarda Çalışanların Öz Yeterliliği: Bir Ölçek Geliştirme Çalışması (Yüksek lisans tezi). Üsküdar Üniversitesi Sağlık Bilimleri Enstitüsü, İstanbul. 